University of Wollongong

Research Online

Faculty of Engineering and Information

Faculty of Engineering and Information

Sciences - Papers: Part A

Sciences

$1-1-2012$

\title{
Analysis of temperature field in liquid-solid bimetal casting of laminated metal composite
}

Xingjian Gao

University of Wollongong, xg306@uowmail.edu.au

Dongbin Wei

University of Wollongong, dwei@uow.edu.au

Zhengyi Jiang

University of Wollongong, jiang@uow.edu.au

Follow this and additional works at: https://ro.uow.edu.au/eispapers

Part of the Engineering Commons, and the Science and Technology Studies Commons

Research Online is the open access institutional repository for the University of Wollongong. For further information contact the UOW Library: research-pubs@uow.edu.au 


\title{
Analysis of temperature field in liquid-solid bimetal casting of laminated metal composite
}

\begin{abstract}
In order to improve the low toughness and poor crack resistance of high chromium cast iron ( $\mathrm{HCCl})$, the laminated metal composite (LMC) consisting of $\mathrm{HCCl}$ and carbon steel has received increasingly attentions in modern industries. Considering that the controllable temperature field at interface of LMC is a key issue in liquid-solid bimetal casting process, a three layered finite element method (FEM) model has been proposed. The influence of parameters including pouring temperature - Tpour, preheating temperature - Tpre and effective volume ratio - VRe on temperature field are discussed. Simulation results show that the temperature at the interface between two dissimilar metals increases with increasing the value of Tpour, Tpre or VRe. Through the adjustment of processing parameters, the contact surface of solid metal can be heated up to mushy state, and then form a thin transient mushy layer. The prefect metallurgical bonding can be achieved by adopting the optimized parameters in bimetal casting process.
\end{abstract}

\section{Keywords}

casting, laminated, metal, composite, bimetal, solid, temperature, liquid, analysis, field

\section{Disciplines}

Engineering | Science and Technology Studies

\section{Publication Details}

Gao, X., Wei, D. \& Jiang, Z. (2012). Analysis of temperature field in liquid-solid bimetal casting of laminated metal composite. Advanced Science Letters, 15 (1), 48-52. 


\title{
Analysis of Temperature Field in Liquid-Solid Bimetal Casting of Laminated Metal Composite
}

\author{
Xingjian Gao*, Dongbin Wei, and Zhengyi Jiang* \\ Faculty of Engineering, University of Wollongong, North-field Avenue, Wollongong NSW2522, Australia
}

\begin{abstract}
In order to improve the low toughness and poor crack resistance of high chromium cast iron $(\mathrm{HCCl})$, the laminated metal composite (LMC) consisting of $\mathrm{HCCl}$ and carbon steel has received increasingly attentions in modern industries. Considering that the controllable temperature field at interface of LMC is a key issue in liquid-solid bimetal casting process, a three layered finite element method (FEM) model has been proposed. The influence of parameters including pouring temperature $-T_{\text {pour }}$, preheating temperature $-T_{\text {pre }}$ and effective volume ratio $-V R_{\theta}$ on temperature field are discussed. Simulation results show that the temperature at the interface between two dissimilar metals increases with increasing the value of $T_{\text {pour }}, T_{\text {pre }}$ or $V R_{e}$. Through the adjustment of processing parameters, the contact surface of solid metal can be heated up to mushy state, and then form a thin transient mushy layer. The prefect metallurgical bonding can be achieved by adopting the optimized parameters in bimetal casting process.
\end{abstract}

Keywords: Temperature Field, Bimetal Casting, Laminated Metal Composite, High Chromium Cast Iron, High Strength Low Alloy Structural Steel.

\section{INTRODUCTION}

In the past five decades, high chromium cast irons (HCCIs) are considered to be one of the most outstanding abrasive resistant materials.' They are widely used in mining, metallurgical and building industries. Very high abrasive resistance and relatively low production costs make $\mathrm{HCCIs}$ suitable for processing abrasive materials such as ore, coal and gravel. ${ }^{1-4}$ Nevertheless, the limitation of the application of HCCIs is caused by their brittleness and low crack resistance which cannot be improved significantly by conventional treatment. Thus, the concept of bimetal casting of high chromium cast iron ( $\mathrm{HCCI})$ and carbon steel has been proposed. ${ }^{5-6}$

However, most previous researches focused on casting techniques and few works have been done on the numerical simulation of the solidifying process of laminated metal composites. ${ }^{5-11}$ Compared with single metal casting, the solidified behavior at the interface between two dissimilar metals plays a crucial role in determining bonding quality and the change of physical and mechanical properties across the interface has a great influence on forming process. ${ }^{12}$ During bimetal casting, the interface can be improved by adjusting parameters such as pouring temperature, preheating temperature of solid metal and the volume ratio of liquid metal to solid metal.

In this work, a three layered finite element method (FEM) model for liquid-solid bimetal casting of $\mathrm{HCCI}$ and high strength

-Authors to whom correspondence should be addressed. low alloy structural steel (HSLA) laminated metal composite has been developed. The FEM software ANSYS was employed in the analysis of temperature field during the laminated metal forming of HBW555XCr21 and E355DD, which are HCCI and HSLA respectively. Optimized processing parameters have been obtained for achieving excellent metallurgical bonding.

\section{MATHEMATICAL MODEL}

\subsection{Bimetal Casting}

As shown in Figure 1, the laminated metal billet is formed by pouring liquid $\mathrm{HBW} 555 \mathrm{XCr} 21$ into mould in which solid E355DD is placed in advance before casting. Considering there are four non-contact zones shown in Figure 1 where E355DD will not bond with $\mathrm{HBW} 555 \mathrm{XCr} 21$, an effective volume ratio of the laminated metal is given in Eq. (1). Prior to pouring, E355DD is preheated to a certain temperature using high frequency induction heating source in the protective atmosphere.

$$
\begin{aligned}
V R_{e}=\frac{V_{\mathrm{HCCl}}}{V_{\mathrm{HSLA}}} & =\frac{a \times b \times h}{2 \times(a \times c 2+b \times c 1) \times h} \\
& =\frac{a \times b}{2 \times(a \times c 2+b \times c 1)}
\end{aligned}
$$

where $V R_{e}$ is the effective volume ratio of liquid metal to solid metal, and $h$ is the length of the billet. 


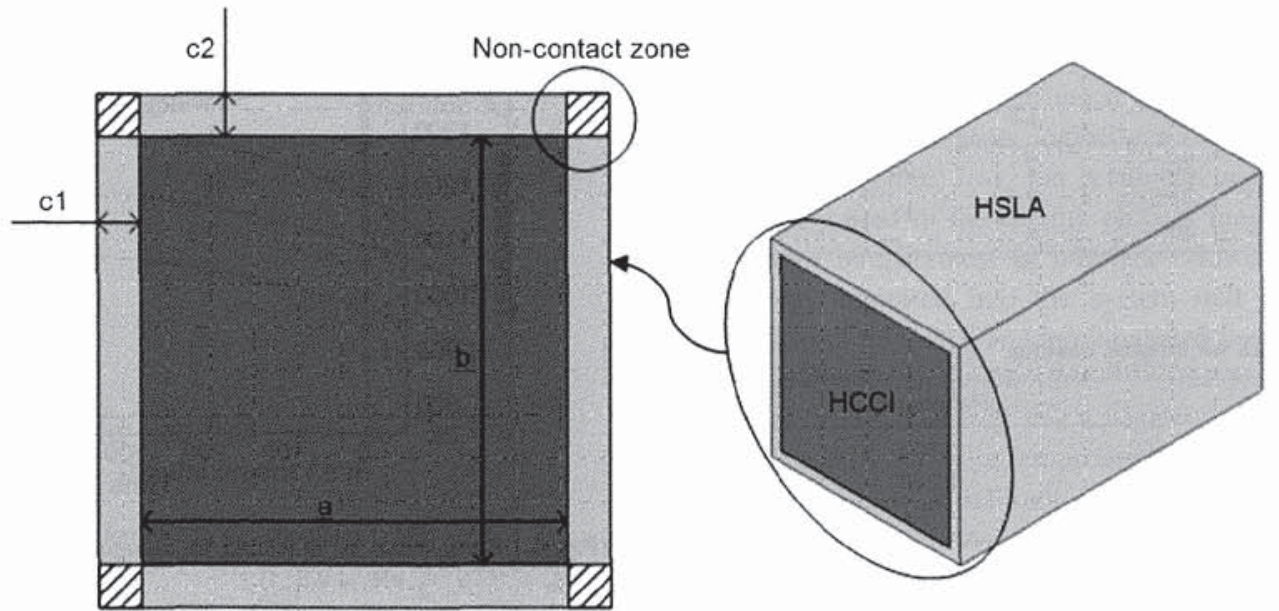

Fig. 1. Schematic of the laminated metal billet.

\subsection{Simulation Methodology}

The temperature field of the interface in casting process was predicted by unsteady state heat transfer analysis using Eq. (2) and the physical properties of the inner and outer layers of the laminated metal billet. In order to simplify the problem, some assumptions have been made:

(1) The solid E355DD placed in advance in the mould can be considered to be a pre-fabricated billet with a homogenous temperature field.

(2) The problem is two-dimensional and the heat transfer in longitudinal direction is ignored.

(3) Heat transfer by conduction in the liquid-solid interface is most important while heat transfer by convection in the liquid $\mathrm{HCCI}$ is neglected due to reduced dimensions of the mould.

(4) Heat transfer by radiation between mould and air is treated as an equivalent convective heat transfer coefficient. ${ }^{13}$

(5) Elastic-plastic deformation in the process of solidification can be neglected.

$$
k\left(\frac{\partial^{2} T}{\partial x^{2}}+\frac{\partial^{2} T}{\partial y^{2}}\right)+\dot{q}=\rho c \frac{\partial T}{\partial t}
$$

where $k$ is the heat conductivity, $\dot{q}$ is the rate of heat generation, $\rho$ and $c$ are density and specific heat of the material respectively. By employing the finite element method and considering the physical properties of alloys as the functions of temperatures, a basic FEM equation for the problem can be derived from Eq. (2).

$$
[C(T)]\{\dot{T}\}+[K(T)]\{T\}=[Q(T)]
$$

where $[C(T)]$ is the heat capacity matrix, $[K(T)]$ is the heat conduction matrix, $\{\dot{T}\}$ and $\{T\}$ are the nodal temperature vector and nodal temperature rate vector, respectively. $[Q(T)]$ is the heat flux vector.

\section{FEM MODEL}

\subsection{Meshing}

Due to the symmetry of the problem, only one quarter of the cross-section is analyzed. As shown in Figure 2, the FEM model includes three different layers which are mould layer, HSLA layer and HCCI layer. The element type of PLANE 55 and overlap method were employed for meshing the layered model. The heat transfer governing equations were solved numerically with the method of variable time step.

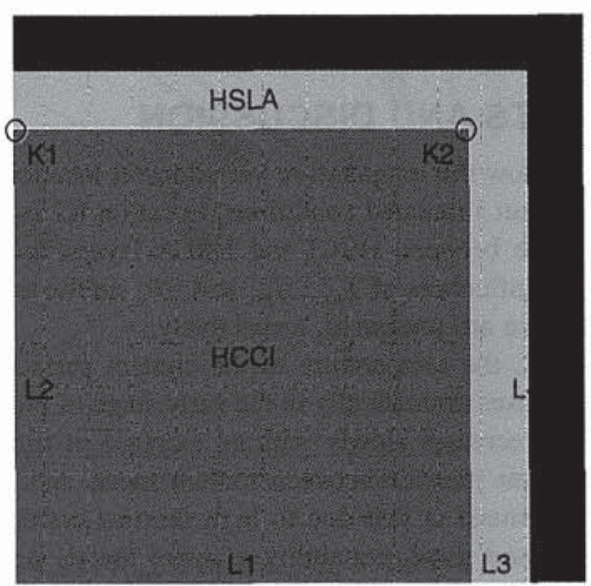

(a) Geometrical model

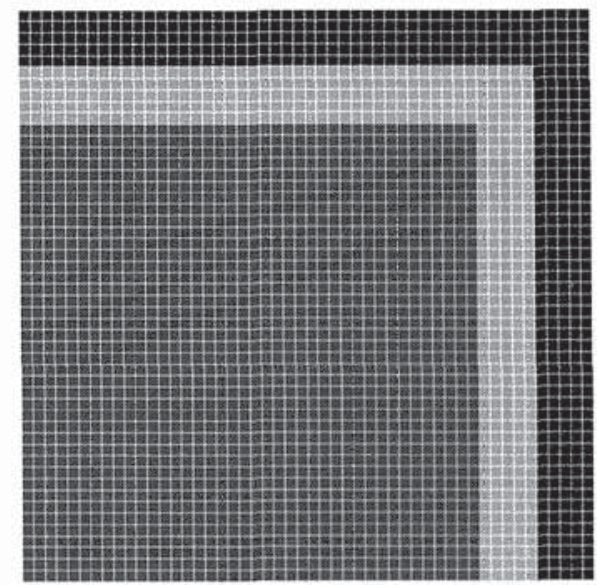

(b) Meshing

Fig. 2. FEM model of the laminated metal billet. 
Table I. Geometrical parameters of mould and LMC billet $(\mathrm{mm})$.

\begin{tabular}{|c|c|c|c|c|c|c|}
\hline \multirow[b]{2}{*}{$V R_{\theta}$} & \multicolumn{2}{|c|}{ HBW555XCr21 } & \multicolumn{2}{|c|}{ E355DD } & \multicolumn{2}{|c|}{ Mould } \\
\hline & L1 & L2 & L3 & L4 & L5 & L6 \\
\hline $9.5: 1$ & 38 & 38 & 2 & 40 & 5 & 45 \\
\hline 7.5:1 & 37.5 & 37.5 & 2.5 & & & \\
\hline $4.5: 1$ & 36 & 36 & 4 & & & \\
\hline
\end{tabular}

Table II. Parameters for bimetal casting.

\begin{tabular}{lccc}
\hline Item & \multicolumn{3}{c}{ Parameters } \\
\hline$T_{\text {pour }}\left({ }^{\circ} \mathrm{C}\right)$ & 1450 & 1500 & 1550 \\
$T_{\text {pre }}\left({ }^{\circ} \mathrm{C}\right)$ & 800 & 1000 & 1200 \\
$V R_{\theta}$ & $9.5: 1$ & $7.5: 1$ & $4.5: 1$ \\
\hline
\end{tabular}

\section{SIMULATION PARAMETERS}

The geometrical parameters used for bimetal casting simulation are listed in Table I. The casting parameters including pouring temperature of $\mathrm{HBW} 555 \mathrm{XCr} 21-T_{\text {pour }}$, preheating temperature of E355DD - $T_{\mathrm{pre}}$ and $V R_{e}$ are listed in Table II. The initial temperature of mould is $25^{\circ} \mathrm{C}$, which is the same as the ambient temperature. The symmetrical boundaries are adiabatic while the outer layer borders are mixed boundary conditions combining convection and radiation.

\section{RESULTS AND DISCUSSION}

Figures 3-5 show the temperature variations at location $\mathrm{Kl}$ with time for different simulated conditions. Location $\mathrm{K} 1$ is the center of the interface between HCCI and HSLA layers, as shown in Figure 2. The influences of $T_{\text {pour }}, T_{\text {pre }}$ and $V R_{e}$ on the temperature field at interface are presented, respectively.

As expected, the temperature at the contact surface of solid E355DD increases dramatically in the early stage of bimetal casting and then decreases slowly with an increase of time. This is because the heat transfer between molten metal and high temperature solid metal is fast due to high thermal conductivity of molten metal and good wettability of solid metal. Besides, the temperature at the interface increases with increasing the value of $T_{\text {pour }}, T_{\text {pri }}$ or $V R_{e}$, which means the interface can be improved by adjusting casting parameters. And it is noted that increasing $T_{\text {pour }}$

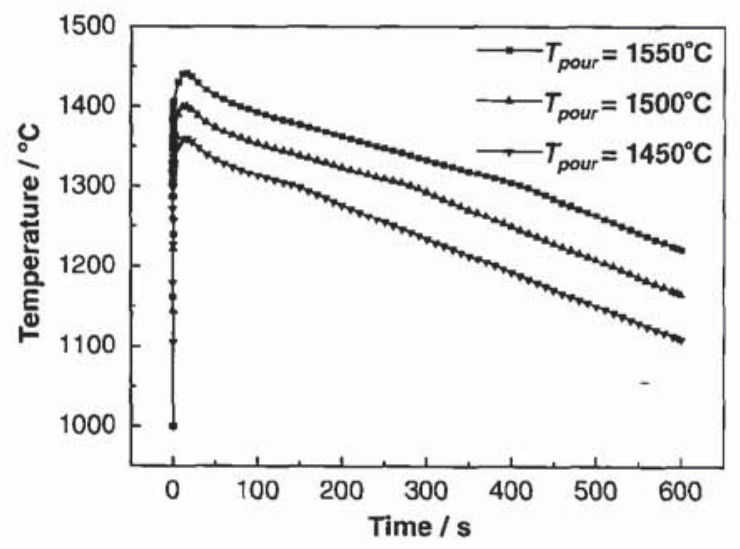

Fig. 3. Comparison of predicted temperatures at $\mathrm{K} 1$ with different $T_{\text {pour }}$ $\left(T_{\text {pre }}=1000^{\circ} \mathrm{C}, V R_{\theta}=4 \cdot 5: 1\right)$.

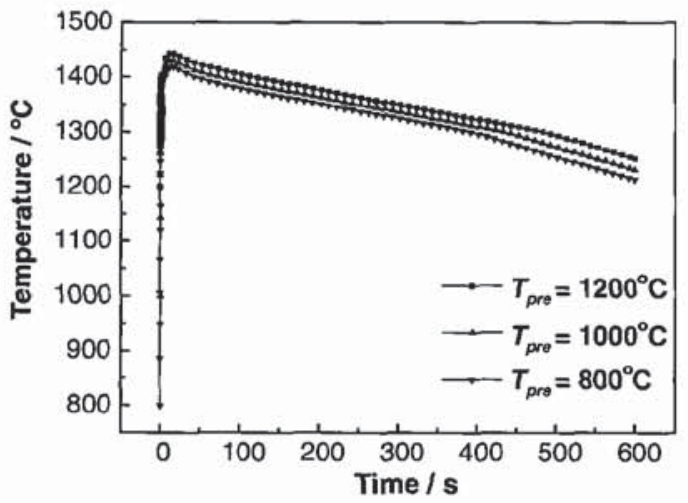

Fig. 4. Comparison of predicted temperatures at $\mathrm{K} 1$ with different $T_{\text {pre }}$ $\left(T_{\text {pour }}=1500^{\circ} \mathrm{C}, V R_{e}=9.5: 1\right)$.

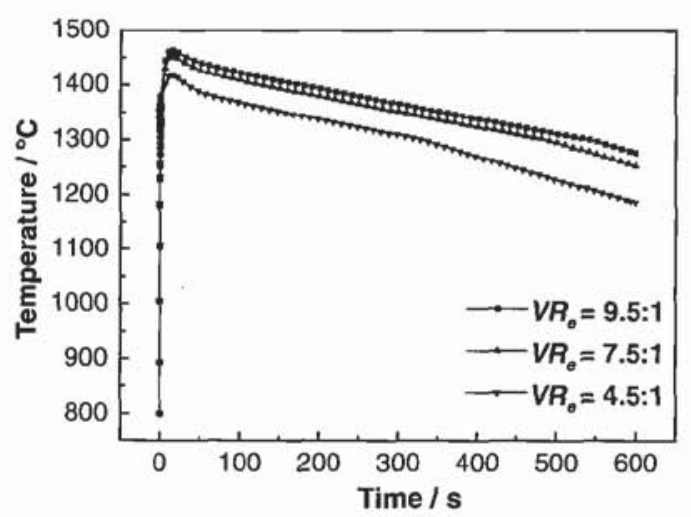

Fig. 5. Comparison of predicted temperatures at $\mathrm{K} 1$ with different $V R_{e}$ $\left(T_{\text {pour }}=1550^{\circ} \mathrm{C}, T_{\text {pre }}=800^{\circ} \mathrm{C}\right)$.

has more significant effect on the temperature field at interface than increasing the other two parameters.

The temperature profiles at location $\mathrm{K} 2$ with time show a similar variation as that at $\mathrm{K} 1$. Location $\mathrm{K} 2$ is the corner of the interface between HCCI and HSLA layers, as shown in Figure 2. However, the temperature values at K2 are always lower than that at $\mathrm{Kl}$, which indicates the temperatures in corner areas are always lower than that in center areas. This is because the heat energy in corner areas is removed from two sides leading to a greater dissipation of heat. Figure 6 shows the temperature profiles from $\mathrm{K} 1$ to $\mathrm{K} 2$ with different simulated conditions when peak temperature is reached. The temperature decreases gradually from center to corner of the interface, which may affect the bonding quality between two metals varies along the contact surfaces. It may be difficult to achieve perfect metallurgical bonding in corner areas.

In order to form an ideal interface, the contact surface of solid E355DD should be re-melted to mushy state. ${ }^{14-15}$ This means the temperature of the contact surface should be heated up to between solidus and liquidus of E355DD by heat transfer from molten HBW555XCr21. The solidus temperature $-T_{S}$ and liquidus temperature - $T_{L}$ of E355DD are calculated on the basis of Eqs. $(4)^{16}$ and $(5),{ }^{17}$ which are $1430^{\circ} \mathrm{C}$ and $1510^{\circ} \mathrm{C}$ respectively.

$$
\begin{aligned}
T_{L}= & 1537-\{88[\mathrm{C}]+8[\mathrm{Si}]+5[\mathrm{Mn}]+30[\mathrm{P}]+25[\mathrm{~S}]+5[\mathrm{Cu}] \\
& +4[\mathrm{Ni}]+1.5[\mathrm{Cr}]+2[\mathrm{Mo}]+18[\mathrm{Ti}]+2[\mathrm{~V}]\}
\end{aligned}
$$




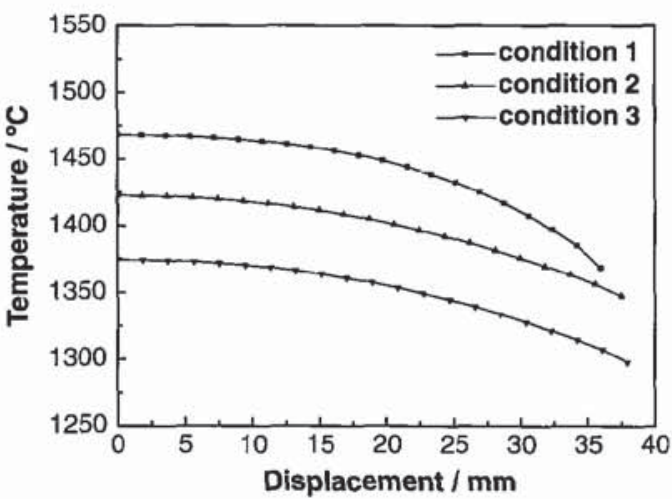

Fig. 6. Temperature profiles form $K 1$ to $K 2$ (condition 1: $V R_{\theta}=4.5: 1, T_{\text {pour }}=$ $1550^{\circ} \mathrm{C}, T_{\text {pre }}=1200^{\circ} \mathrm{C}$; condition 2: $V R_{\theta}=7.5: 1, T_{\text {pour }}=1500^{\circ} \mathrm{C}, T_{\text {pre }}=$ $1000^{\circ} \mathrm{C}$; condition 3: $V R_{\theta}=9.5: 1, T_{\text {pour }}=1450^{\circ} \mathrm{C}, T_{\text {pre }}=800^{\circ} \mathrm{C}$ ).

$$
\begin{aligned}
T_{S}= & 1538-\{175[\mathrm{C}]+20[\mathrm{Si}]+30[\mathrm{Mn}]+280[\mathrm{P}]+575[\mathrm{~S}] \\
& +4.75[\mathrm{Ni}]+6.5[\mathrm{Cr}]+5[\mathrm{Mo}]+40[\mathrm{Ti}]+4[\mathrm{~V}]\}
\end{aligned}
$$

Figures 7(a)-(c) show the contour maps of temperature field of laminated metal billet with different simulated conditions when the temperatures at interface reach peak. Although some scatter is apparent, these plots logically show diagonal symmetry. As shown in Figure $7(\mathrm{a})$, the relatively high values of $T_{\text {pour }}$, $T_{\mathrm{prc}}$ and $V R_{e}$ used in the casting process may result in the relatively high temperatures at interface. However, an excess of heat energy imported into the system will lead to excessive fusion of solid E355DD, and the laminated metal composite may become gradient metal composite. ${ }^{18-19}$ Besides, too much superheating of $\mathrm{HBW} 555 \mathrm{XCr} 21$ has a negative effect on grain refining. Figure 7(b) shows a temperature field with relatively low temperature values, which indicates an unsatisfied bonding may be produced because too low temperatures at the interface to form mushy state. Figure 7 (c) shows a satisfactory temperature field with appropriate temperature values. It is worth noting that when the optimized processing parameters such as $V R_{\mathrm{e}}=4.5: 1$, $T_{\text {pour }}=1550{ }^{\circ} \mathrm{C}, T_{\text {pre }}=1000^{\circ} \mathrm{C}$ are adopted in bimetal casting, the bonding quality may be improved significantly. This is

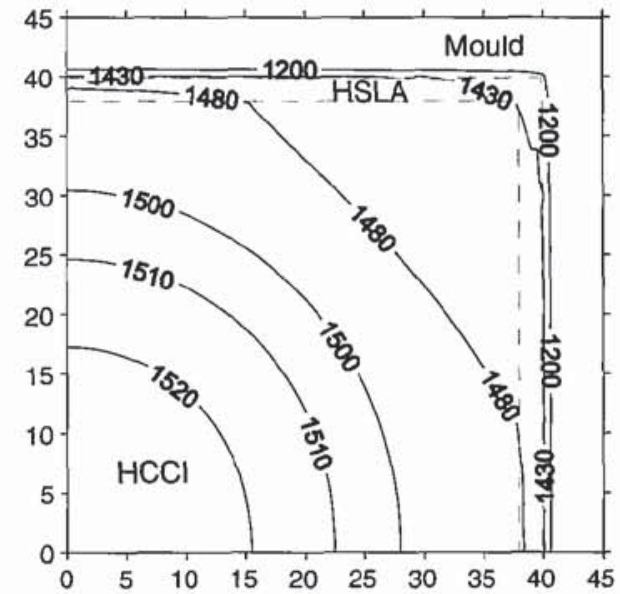

(a) $V R_{e}=9.5: 1, T_{\text {pour }}=1550^{\circ} \mathrm{C}, T_{\text {pre }}=1200^{\circ} \mathrm{C}$

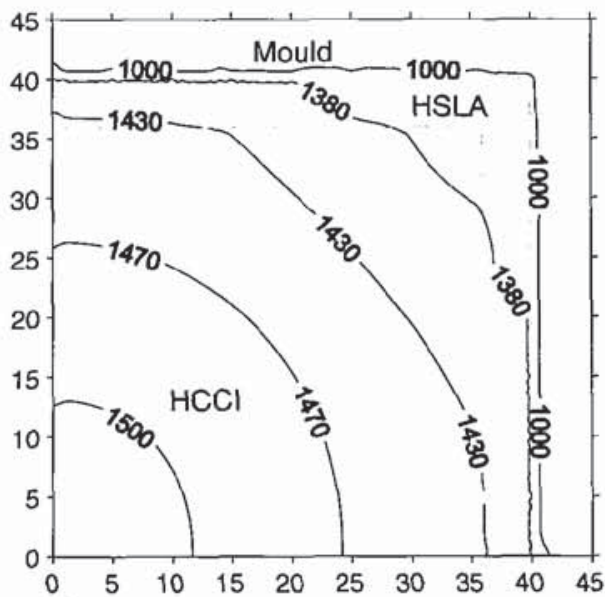

(c) $V R_{e}=4.5: 1, T_{\text {pour }}=1550^{\circ} \mathrm{C}, T_{\text {pre }}=1000^{\circ} \mathrm{C}$

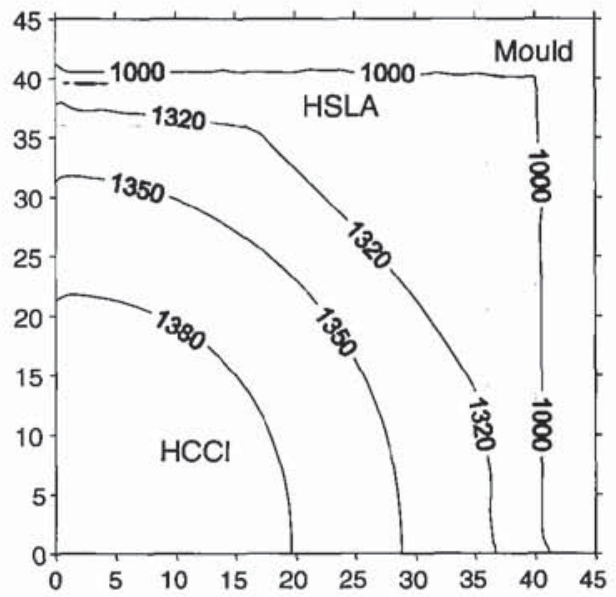

(b) $V R_{e}=4.5: 1, T_{\text {pour }}=1450^{\circ} \mathrm{C}, T_{\text {pre }}=800^{\circ} \mathrm{C}$

Fig. 7. Contour plots of temperature field of laminated metal billet. 
because a thin transient mushy layer may be formed in center areas on the contact surface of solid E355DD.

\section{CONCLUSIONS}

(1) A three-layer FEM model for liquid-solid bimetal casting of HCCI and HSLA laminated metal composite has been developed. The model can be used to optimize processing parameters including pouring temperature, preheating temperature and effective volume ratio for achieving perfect metallurgical bonding.

(2) The temperature at the contact surface of solid E355DD increases sharply in the early stage of bimetal casting and then decreases slowly with an increase of time. Increasing the value of $T_{\text {pour }}, T_{\text {pre }}$ or $V R_{e}$, the temperatures at interface may increase due to incremental heat energy imported into the system. The change of $T_{\text {pour }}$ has more significant influence on the interface temperatures.

(3) The perfect metallurgical bonding for laminated metal composite can be achieved by adjusting processing parameters. The optimized parameters employed in bimetal casting may produce a thin transient mushy layer at the interface to ensure the bonding quality.
Acknowledgments: The first author would like to appreciate the China Scholarship Council (CSC) for supporting the current research work.

\section{References and Notes}

1. A. Sinatora and M. Pohl, Scr. Metall. Mater. 32,857 (1995).

2. O. N. Dogan, J. A. Hawk, and G. Laird, Metall. Mater. Trans. A 28,1315 (1997).

3. K. H. Z. Gahr and G. T. Eldis, Wear 64, 175 (1980).

4. i. Fernandez and F. J. Belzunce, Mater. Charact. 59, 669 (2008).

5. 8. W. Xiong and C. C. Cai, Mater. Des. 32, 2978 (2011).

6. G. L. Xie, H. Sheng, and J. T. Han, Mater. Des. 31,3062 (2010)

7. M. Hashimoto and S. Otomo, ISIJ int. 31, 1202 (1992).

8. T. Haga and S. Suzuki, J. Mater. Process. Technol. 138, 366 (2003).

9. M. S. Singh, R. K. B. Singh, and R. Khatri, Adv. Sci. Lett. 3, 57 (2010).

10. E. Takeuchi, M. Zeze, and H. Tanaka, Ironmaking Steelmaking 24, 257 (1997).

11. N. Mathew, Z. Y. Jiang, and D. B. Wei, Adv. Sci. Lett. 4, 3243 (2011).

12. M. Simsir and L. C. Kumruoglu, Mater. Des. 30, 264 (2009),

13. B. D. Alvarez, J. L. F. Martinez, and M. L. G. Martin, Finite Elements in Analysis and Design 33, 43 (1999).

14. R. B. Wagstaff, D. J. Lloyd, and T. F. Bischoff, Mater. Sci. Forum 519, 1809 (2006).

15. M. D. Anderson and K. T. Kubo, Method for Casting Composite Ingot. U. S. Patent 2009/0145569 A1, Jan. 6 (2009).

16. J. M. C. Marrero and V. C. Galindo, ISIJ Int. 38, 812 (1998).

17. J. X. Chen, Metallurgical Industry Press, Beijing (1984). (In Chinese)

18. D. R. Lesuer and C. K. Syn, Int. Mater. Rev. 41, 169 (1996).

19. J. Wadsworth and D. R. Lesuer, Mater. Charact. 45, 289 (2000). 